\title{
EDUCATION OF YOUNG PEOPLE AND CHILDREN AS A WAY OF FIGHTING AGAINST INTERNET HATE, A FORM OF CYBER VIOLENCE
}

\author{
Marek Górka \\ Faculty of Humanities \\ Koszalin University of Technology \\ 6d/7 Kwiatkowksiego str., Koszalin, Poland, 75-343 \\ marek_gorka@wp.pl
}

\begin{abstract}
Due to highly innovative technologies such as the smartphone, cyber- bullying and on-line, aggression has increasingly affected individuals across the world. Cyber-bullying is defined as repeated unwanted, hurtful, harassing, and threatening interaction through electronic communication media. Anonymity and mobility afforded by the Internet have made harassment and expressions of hate effortless in a landscape that is abstract and beyond the realms of traditional law enforcement. Further, it argues that a broad coalition of government, schools, police and citizenry is likely to be most effective in reducing the harm caused by hate speech. The study discusses the targets of hate on the Internet, provides a framework within which problems can be identified and resolved by accentuating moral and social responsibility, and articulates possible solutions to combat with this increasing problem.
\end{abstract}

Keywords: cyber-bullying, digital aggression, Internet, online bullying, online protection, young people.

\section{Introduction}

The e-world of many opinions is expanding more and more, just as the access to the Internet is. Unfortunately, this world of electronic opinion is the so-called e-world of hate, which is being used by almost all social groups, regardless of age, level of education, sex or place of residence. Hate appears in every field of life; it is present not only on gossip websites but also in politics. It has also forced its way into scientific and literary discourse. It is present in comments on human tragedy, where one would expect serious behavior and being compassionate towards others. It is worth mentioning that the Polish society is not much different in such behavior as it is not a matter of a specific country. Hate is visible almost worldwide. Verbal aggression in cyberspace is also used by young people [1].

Most Internet users encounter hate, i.e. malicious, unfair, often vulgar language. More and more cases of hate-based offences are reported to the police. According to police statistics, these offences very often meet the criteria of a prohibited act - stalking (harassment, sometimes even threats, sometimes insults). The police seizes given websites and data carriers in order to present the evidence in court. Virtual hate is aimed not only at politicians, celebrities, journalists, bloggers, public figures but also at average Internet users [2].

On the basis of discussion, also present in mass media, a question arises: which institutions should deal with this problem? Should these be the police, the prosecutor's office or maybe the educational facilities or perhaps the academic world? How to react to these hate phenomena? When might a young person become a victim of hate? What form of schooling and social education can help minimize this phenomenon? This paper shall try to answer the questions stated above.

The article comments upon a part of the results of a project entitled ,Education for cyber safety" introduced in upper-secondary schools. The analytical research dealt with a wide notion of cyber threats present in a group of pupils and students learning in West Pomerania Province schools in Poland, and was also a part of cooperation of many public institutions. The interaction of academic society, the police and school employees is an opportunity to compare and exchange information about the efficiency of actions for minimizing threats in cyberspace.

Apart from many dangers which appear in cyberspace, the results of research have shown the presence of aggressive and hateful content used by young people on the Internet. This research is, therefore, an attempt at reaching young people's minds (especially those people who experienced hate both as victims and assaulters). The knowledge gained (especially from the latter group) is a 
result of various surveys and individual interviews conducted. The friendly and open cooperation of school employees has proven to be very helpful as they shared their knowledge about victims of hate in cyberspace and they let them be interviewed. A vital part of research is the contact with young assaulters who were putting aggressive content on the Internet. The information on those people was handed in via school counselors; the assaulters were also interviewed and surveyed. The feedback obtained allows building up a certain motivation background which made those young people use Internet aggression and it helps selecting the main causes of this phenomenon.

Education for cyber safety plays a major role in prevention. Its aim is to make young people aware of how malicious Internet hate is. Of course, it is not the only element enhancing education for cyber safety and acting against Internet hate. Education for tolerance is also important, because people who are in some ways different than others are most often subject of hate [3].

The goal of classes conducted in schools was making young people aware of what hate is and how they should react if they experience it. This kind of knowledge might be of help for the teachers who prepare various classes on cyber safety.

As the statistics shows, 40 percent of students claim to have observed hate online [4]; massive hate seems to be especially dangerous. We may speak of cyber violence when a young person is attacked, particularly by his or her peers, and when his or her appearance or skills are negatively judged. Young people see themselves through the eyes of their peers and that is the problem which sometimes leads to tragic consequences.

Hate on the Internet is an issue which the state has not dealt completely with. Prosecutors happen to react on various occasions, especially when there are cases of racial hatred. Monitoring the Internet is very difficult, though.

In the fight against hate speech on the Internet, close cooperation between Internet users and the state is necessary. With today's technical possibilities, locating the offender is not an issue. The data gathered at the county police headquarters in West Pomerania Province show that the number of reported cases and ,guilty" verdicts increases. This fact might be treated as a positive sign that the social feeling of impunity among Internet users will be less intense and that the arrogance allowing certain individuals write virtually everything on the web will be gone [5].

\section{Aim of research}

It is anticipated that knowledge gained from this study through data collection and analysis will provide students, educators, parents, and other educational stakeholders with an understanding of the perceptions of students on the effects of cyber-bullying, the frequency of incidents, and ways in which to report them positively.

\section{Definition of hate on the Internet}

Hate is a universal problem among all humans and it evolves in a very dangerous way. Just a few years ago it was something embarrassing. It was believed that people express their extreme opinions on the World Wide Web because of its anonymity; nowadays people do that not only under their real names but they add and expose their real photos, too. Hate became completely open. The line of embarrassment, which surrounded extremely hateful opinions, was crossed [6]. It is worth considering when and why this line was crossed. One could see the gradual process of social assent to hateful behavior on the Internet, thus making it ,legitimate”. Victims of Internet hate are unable to defend themselves which leads to expansion of hate over the Internet.

But hate came out on streets, too. What seemed to go unpunished on the Net (even if haters would put their real names under their posts), now found its ground in the real world. Therefore, expressing extreme and aggressive views on the Internet encourages people to use hate in reality [7].

People who express their extreme opinions and find their own followers on the Internet are able to see more of their kind; they are able to channel their hatred towards one, common direction. World Wide Web facilitates communication making it easier to gather and demonstrate while using hateful slogans prohibited by Polish law. The Internet constitutes a kind of a network for such behaviors. It is also worth mentioning that through expressing hatred people satisfy one of their basic needs - the need of being accepted. The innate element of human nature is the fact 
that negative messages draw people's attention more [8] What also needs to be said aside is the fact that political campaigns are great examples of how easy it is to gather citizens ,,against" rather than ,for” a given cause.

Social networks form groups of people whose main idea is to show and prove their own superiority over others. The other factor - following the efforts of boosting their self-esteem - is conformism which comes from the need of being accepted by people of similar views and interests. Therefore, hate is not just a fad. This phenomenon is quite deeply rooted in culture and in human way of reacting to the environment. For if a man feels helpless, he searches for a way of venting his frustration, anger and dissent from the current reality. Hate is a typical social phenomenon; it is a group process, because the man is a social animal. Hatred is present where groups of people are, or where people try to find out who is „one of us” and who is „one of them”. It is natural for dislike to appear, but it may take the pathological form of hate [9].

If a group of people agrees (one way or another) they do not like somebody or something, it is very probable that their lack of acceptance will lead to hate. The final stage of each process of hating is the desire to annihilate the hated person. Fortunately, the Internet-based hate is rather far from exercising that final stage most of times, but there are cases of suicides resulting from being hated [10].

The fight against negative phenomena on the Internet is a question of managing groups in such a way they would not base their actions on negative attitudes and reactions. Criticizing is not wrong as long as the expressed opinion is not a hotbed of a group process. If that happens, though, there may appear a group which has its own symbols, identity and is almost sure to attack verbally. Then, from the verbal and symbolic stage it may move forward to the physical attack stage. The result of such situation is a very strong group which finds a very weak victim and, one way or another, destroys the victim ultimately. And the Internet only facilitates that because anyone can influence the content shown on websites (texts, movie clips or cartoons). Thus, hate may take the form of images (these can be memes, pictures) or movie clips with appropriate commentary. It appears, then, that when it comes to hate, only the sky's the limit [11].

Internet hate can be an introduction to hate speech, which is understood as a way of promoting or justifying certain content towards a given person or group of people as far as race, color of skin, nationality or ethnic background is concerned [12]. Thus, this phenomenon concerns certain groups or social categories. Those two aspects, hate and cyber violence, can be linked together as more and more frequently there appear in Polish schools students of different color of skin or ethnic background. It may appear that such people can be more prone to hate as they are more distinctive, focus aggressive behavior and become scapegoats. The roots of hate may also be found in attitudes presented by adults - children hear how their parents talk about people of e. g. different race and simply repeat what they have been taught.

Hate can be perceived by its victim in many different ways - for a given person these can be vulgar insults, for another a single, negative comment on a social network website. Where is the difference between criticism and hate, then? Is all criticism hate? Criticism is expressing one's opinion with the use of arguments, while hate is plain judging with the use of insults. The results of commentary analysis on the Internet show that there is a relation between calling something „criticism” or „hate”, depending on who is judging - if we are being criticized by „them” then it is „hate”, and if we are being openly hateful towards „them”, we usually call that „,criticism”.

\section{Causes of hate}

The recent flood of hate is clearly visible. A dozen or so years ago the Internet content was not as full of hate and violence as today. Discussion beneath the articles was substantive and significant, message boards were friendly, but nowadays there are more users who criticize the authors of given pieces of news. Hate is nothing new, it was present in public life long before the Internet was born. Such hateful way of expressing one's opinion became easier because users think they can remain anonymous on the Internet [13].

What is the main cause of hate? As the survey shows, the main motive ( 7 out of 10 people) for hating is the opportunity to relieve the tension and getting rid of frustration. A half of cases of 
aggressive behavior is aimed at random people. The other reason for hate speech in cyber space is the desire to hurt and humiliate people. We need to mention the so-called ,cockpit effect” while we talk about such mechanisms of hating. The person hating other people cannot see the victim and his/her reactions; 6 out of 10 haters said they would have stopped their assaulting, if they had seen the suffering of their victims. A similar effect can be observed in the case of a car driver who would insult other drivers more, if he/she sat inside the car rather than do it face to face. It appears that cyber-bullies are not aware of the consequences of their actions and thus they feel even more motivated.

Four answers by ex-haters are especially disturbing. It seems that inability to see the victim's reactions is not the only reason why hate spreads throughout the Internet. On the contrary; in the case of the above mentioned four assaulters, research shows that they feed on reactions and suffering of their victims. They do it to get satisfaction which appears when they know their victim is hurt.

The increase in verbal violence also results from haters' helplessness. It is, thus, a way of fighting for being respected in their environment. This can be done in a face to face confrontation or in a safer way - via the Internet, where they cannot get hurt physically.

In a way we can observe a similar phenomenon among adults. A group of frustrated people is getting bigger, they cannot cope with the pace of life and the goals life sets for them. These are not people worse-off or poorly educated - they are only, for some reason, dissatisfied with their lives. They try to make their personal images better by hurting other people, so those other people are weaker too and do not stand out from their ,crowd” [14].

If hate speech is aimed at ethnic minorities, then some people start to believe that the language mirrors thoughts and social attitudes of a given group. Sometimes hate is a way of gaining power over the other group of people, a form of justifying their worse position (on ethnic or religious grounds). Lack of control over the course of actions and the feeling of helplessness may strengthen some biases against certain groups hence making the desire to use insulting language stronger [15]. The reason why we are dealing with such amount of verbal violence on the Internet might be quite puzzling. It is the result of people's emotional state but also of the feeling of being anonymous [16].

Hate results not only from the Internet's nature; the Internet tends to be less anonymous nowadays. There are social network websites where users have their own names; more and more news bulletins use comments which are put via social network websites, so being anonymous is probably not the main reason. Hating uses the so-called „snowball effect” which fights aggression with aggression, and as it often seems, this is exactly what haters want and need.

Offensive posts were always present in public life, but with the change in mass media and the way information became available to people, they reach everyone much faster now. The media often tend to transform pieces of news on cyber-bullying into a sensational, tabloid form making thus hate even more popular.

\section{Hate speech}

The thesis stating that today's vulgar and offensive Internet language affects its victims more than the insulting language present a decade ago on city walls or in school bathrooms is worth considering. Insults are a kind of a symbol of violence subject to interpretation. The Internet, however, makes insults more accurate and intense, because it is a great source of information. A survey carried out on ex-haters showed that 7 out of 10 haters gathered and used personal information found on social network websites. In other words, these were not just random insults but carefully selected blows aimed at the victim.

There is also a problem with the victim's interpretation, because the electronic content usually lacks context, causes fear of further attacks, and one cannot see the opponent's face (unlike the real world quarrels). On the Internet one cannot be sure whether hate speech is articulated on the spur of the moment or it is just the beginning of a longer hate process and a kind of a strategy.

Should we want to look at how hate speech works, we need to think about its driving force - does the way we speak, words we use influence our behavior and what we think and how 
we interact with others? On the one hand, the language we use tells much about us; on the other hand, very often we tend to behave according to the language we use. For instance, a person behaves differently, walks differently when wearing smart clothes and work clothes respectively. We can assume that a similar process takes place in language terms. Do specific environments and their lingos require their members to behave in a specific way, then? We function in a world which communicates with us in a given manner, so even smart clothes can be sometimes inappropriate.

\section{The haters}

There is a lot of tragic news in the media on the victims, but it is worth giving some thought to who the haters are or whom they might be. They are not a large group among schoolchildren. Only 10 out of 920 students admitted to have been posting hate on the Internet. Of course, there are probably more people like those - they might not have admitted to or are unaware of posting hate messages. Nevertheless, we can say that such people are overrepresented in places where hate speech appears.

Who are the haters? How old are they? What kind of people are they most often? Apparently anyone can be a hater, sometimes even without realizing it. The moment when a malicious comment is sent or liked is crucial here - it is when a user, unconsciously, becomes a passive participant of hating. It is difficult to say who the haters are; they are hard to identify because they do not want to reveal their identities to researchers. If around a negative attitude there appears a group of people, it is almost sure that, in a course of group processes, the negative attitude will turn into hate. On the Internet, it can be easily observed among teenagers.

\section{The importance of parents}

Social campaigns and classes in schools are of great help in education for cyber safety project. These are only elements of the whole process; parents and institutions (the police, organizations and foundations dealing with cyber safety, as well as the academic world) play also a major role in understanding processes of cyberspace [17].

The Internet has become a medium widely used by young people and, probably, that is why many dangerous things happen there (even more dangerous than in reality). In reality, parents have more influence on their children's safety, whereas in the virtual world they are unable to control their children's actions.

Surveys show that almost three fourths of parents think they are able to control what their children do on the Net. Those parents are satisfied with their children sitting at home, not having to worry that their kids will end up run over by a car. It is, obviously, an illusion which many institutions have been trying to fight with for years, because we never know what content the child is exposed to, and people on the Internet not always mean no harm.

There are a lot of threats on the Internet which a young person may encounter: cyber-bullying or malicious content which can leave mental scars. Research shows that almost 90 percent of young people under 18 visit websites which are clearly labeled,,adults only”. It appears that the forbidden fruit tastes the sweetest. That is, probably, the reason why so many young people under 18 are addicted to pornography. Over half of young people, that is 60 percent of the polled, admith ted to have been visiting porn sites at least three times a week. Young people look for information on their sexuality and the Net is a convenient source of information for them; they do not have to ask their parents personally, especially when the topic is quite embarrassing.

If a computer is not protected with ,parental controls”, and the parents do not know what their children do exactly, then there is a great probability that children might get exposed to malicious content (violence, pornography). The parents can try to control what their children do on the Internet, but that is quite challenging because nowadays every smartphone can go on-line almost instantly. Turning the computer off is the fastest way of dealing with the problem but it does not solve its cause. What has been sent on-line stays on-line (including comments and images), so going off-line is not a permanent solution.

In both virtual and real life it is impossible to protect children from everything. What can be done, though, is to give children the knowledge of what is right and what is wrong, how to behave to 
avoid dangers and where to look for help [18]. So when it comes to young people's safety education and talking to children are crucial. Also, cooperation between parents, teachers, NGOs, the police and academic institutions is important.

\section{Methods of protection against hate}

There is a popular belief that says not to fight fire with fire, i. e. not to react aggressively when attacked. However, some kind of reaction is necessary. The question is: what kind of reaction? The knowledge about methods and ways of reacting to hateful comments has been gathered with the use of information obtained from surveys conducted on students who experienced hate, and teachers as well. Thus checked and confronted method of reacting shows the efficiency of certain reactions to specific social behaviors in cyberspace.

- One of the methods is ignoring the haters, because they want confrontation and discussing with them is futile. Among the polled, 40 percent of those who tried this method said it was the most efficient and hurt haters the most.

- Another method is answering without personal engagement in discussion. It is important that there are some other people who would clearly make their stand against the hater. Almost all respondents who experienced cyber-bullying highlighted the importance of peer support on social network websites. It appears, then, that leaving hate without any reaction is not the best way of fighting against this phenomenon. It is a good idea, in some instances, to draw the line and say: „I do not wish to have such comments" and ,you can't talk to me like that"; sometimes ignoring the problem does not work. All school counselors pointed that reporting the problem and looking for help is usually the best solution. Reacting emotionally is natural in this kind of situation, but it does not deal with the problem. It is very important not to be left with emotions alone but talk to a friend or a person close to us or even use a help line.

- What can be done if other users behave too aggressive and overwhelming? The research shows that the above mentioned method is effective, i. e. the attacked person needs to set a limit in his/her cyber-personal space and say „no”, „I don't like that”, „I don’t want that”, „what has been shown was not meant for your eyes".

- NGOs, schools, the police and the prosecutor's office should treat the problem seriously and support victims of hate making them stronger so they can be a match for the haters.

- Police officers who deal with cyber-bullying say that most social network websites allow reporting inappropriate comments. It is important to let the site administrator know about the problem because if it is not done, nobody will be able to react properly. The need of registering user accounts on various websites is a way of protecting against hate but most of times it is not a good way to stop hate speech in cyberspace.

- It is possible to avoid hate but you need to use one method of protection which is simply not visiting certain websites because some of them promote or were created to voice hateful content. Of course it does not guarantee us being free from insulting comments whatsoever.

Appropriate institutions should monitor cyberspace content and impose adequate pressure on perpetrators. There are certain rules and regulations but, in practice, they do not always work and apply. The research shows that sometimes government officials do not understand the case fully and treat Internet hate as inoffensive jokes. They admit they are often flooded with reports on hateful comments. Lawyers, in a way, might feel the same way as they have to deal with more drastic cases. Thus a kind of indifference towards these forms of aggression is created.

People who are better-off are able to get help from lawyers and even politicians to fight against hate on the Internet. An average citizen has it more difficult, no matter if the arguments are strong enough to start reacting seriously or not.

\section{Result of research}

On the basis of the research and talking to school employees directly it can be concluded that although teachers and school counselors see the problem, they do not cope with it completely. However, they express a great readiness and will to cooperate with various public institutions as far as cyber safety is concerned. Hate in schools is not a new phenomenon. But in today's global soci- 
ety some negative behaviors are transformed from virtual life into reality and very often victims of cyber-bullying experience similar violence at school [19].

The hating process begins with ,stigmatizing” a person. Very often this is a new, weaker student or a person who looks different than others and who is unable to face the crowd. School employees noticed the lack of openness from groups of students who do not accept any new members and do not cooperate with school authorities. This is a challenge for the researchers as understanding how such groups function is the key to understanding hate speech mechanisms.

Convincing young people that hate is wrong is very difficult. Indifference is quite noticeable, just as adults seem to tolerate drunk drivers or ignore people lying on the streets. It appears that teaching responsibility and empathy needs to be a part of citizenship education process.

Unfortunately, hate is continuing in adult life. That is why education for cyber safety is so important as far as citizenship education is concerned. School counselors stress the role of the „eyewitness" who can do much because, on the one hand, he/she can join in hating unconsciously and play the role of a passive aggressor; on the other hand, he/she is afraid of being rejected by the group and joins the stronger ones. But such a ,witness” can also say „no” and report the situation to real or virtual authorities. The victim, whereas, should get support from ,,peer-witnesses”, parents and school employees.

Is looking for help telling on someone, is it informing against somebody? The answer is not so obvious because the victims fear their peer-aggressors the most. Victims tend to think that they will never be able to have friends at school. Victims of hate, in surveys, said that they had such fears at the beginning. That is why they could not see any hope for resolving the problem and the matter was getting even worse.

It can be said that young people have much sensitivity. They pay a lot of attention to what their image on the Internet is; the Net plays a major role in their lives. They cannot distance themselves from virtual content, because their presence in cyberspace is more emotional and intense than their parents or their grandparents. Young people share a lot of their privacy: photos, movies - they treat these as their real life. They tend to believe more what is said in the comments below a given article if they know less about the article itself. It turns out that every fifth comment on social network websites or web chats where young people dominate is an insult.

A young person does not have his/her own opinion or adequate self-esteem. Therefore, the violent cyberspace attacks hurt young people the most. The polled pointed to aggressive feedback, concerning things which young people think of as their creation, as most damaging. If a student is insulted in school and rejected by his/her peers, then he/she becomes a "scapegoat". The ostracism follows him/her to the Internet and then waves of hate really hit social network websites [20].

The worst you can do is give hate feedback (i. e. like and share hateful comments). No reaci tion from other users is also bad attitude. A real problem lies in understanding how young people perceive and use the Internet, because older generations did not grow up with it and had some time to have their social life formed. Young people do not divide their life into „online” and „offline” so it is harder to educate them, nor can the Internet be taken away from them as it is part of their environment. They do not understand that it is the real human being who types and who reads comments facing the consequences in real life.

It is crucial to convince young people that hate does do harm. Young people do not realize that what they do brings consequences, because this phenomenon begins with a harmless joke. Young people do not realize that it may turn into a bigger conflict and then escalate. It turns out that giving tragic and straightforward stories (told by former victims) as examples, and also trying to empathize with the victims, brings good results.

\section{Conclusion}

1. Internet hate is equal to traditional hate present in schools and at the playgrounds. It dife fers from the traditional bullying because of lack of boundaries and because of the level of anonymity and dynamics. Cyber-bullying goes far beyond face-to-face aggression which we can observe in schools because thanks to mobile phones it can be performed at home. Social cruelty of children, 
so present in text messages, e-mails, messengers and web chats, has become too widespread. Education seems to be the key to solving the problem of Internet hate.

2. There is much to do as far as education for functioning in cyberspace of young people is concerned. Carrying out the education for cyber safety project is aimed at making young people aware that even if today somebody else is a victim of cyber-bullying, the other day this can be any of us. So, can we influence the society in any way and prevent this negative phenomenon? What prevents us from hating the others is the awareness of the fact that expressing hate makes people bad and that hate is the worst of all feelings a man can share.

\section{References}

[1] Whittaker, E., Kowalski, R. M. (2014). Cyberbullying Via Social Media. Journal of School Violence, 14 (1), 11-29. doi: 10.1080/15388220.2014.949377

[2] Olweus, D. (2012). Cyberbullying: An overrated phenomenon? European Journal of Developmental Psychology, 9 (5), 520-538. doi: 10.1080/17405629.2012.682358

[3] Gradinger, P., Yanagida, T., Strohmeier, D., Spiel, C. (2014). Prevention of Cyberbullying and Cyber Victimization: Evaluation of the ViSC Social Competence Program. Journal of School Violence, 14 (1), 87-110. doi: 10.1080/15388220.2014.963231

[4] Speaking against intolerance, hatred. Available at: http:/www.mowanienawisci.info/sekcja/polska/

[5] Banks, J. (2010). Regulating hate speech online. International Review of Law, Computers \& Technology, 24 (3), 233-239. doi: 10.1080/13600869.2010.522323

[6] Rafferty, R., Vander Ven, T. (2014). "I Hate Everything About You": A Qualitative Examination of Cyberbullying and On-Line Aggression in a College Sample. Deviant Behavior, 35(5), 364-377. doi: 10.1080/01639625.2013.849171

[7] Jaishankar, K. (2008). Cyber Hate: Antisocial networking in the Internet. International Journal of Cyber Criminology, 2 (2), 16-20.

[8] Perry, B., Olsson, P. (2009). Cyberhate: the globalization of hate. Information \& Communications Technology Law, 18 (2), 185-199. doi: 10.1080/13600830902814984

[9] Guichard, A. (2009). Hate crime in cyberspace: the challenges of substantive criminal law. Information \& Communications Technology Law, 18 (2), 201-234. doi: 10.1080/13600830902814919

[10] Campos, A. (2013). Cyber bullies drove my son to the brink of suicide: investigates online hate campaigns. Sunday Mirror, 12.

[11] Cohen-Almagor, R. (2011). Fighting Hate and Bigotry on the Internet. Policy \& Internet, 3 (3), 89-114. doi: 10.2202/1944-2866.1059

[12] Meddaugh, P. M., Kay, J. (2009). Hate Speech or "Reasonable Racism?" The Other in Stormfront. Journal of Mass Media Ethics, 24 (4), 251-268. doi: 10.1080/08900520903320936

[13] Brown, S., Bellinger, L. (2000). Virtual hate. Sojourners, 29 (5), 18-23.

[14] O’Dea, N. (2013). Culture Of Hate: Cyber-Bullying And Sexting Part 1. Vermilion and Area Voice, A.22.

[15] Awan, I. (2016). Islamophobia on Social Media: A Qualitative Analysis of the Facebook's Walls of Hate. International Journal of Cyber Criminology, 10 (1), 1-20.

[16] Hicks, J. F., Clair, B., Berry, S. (2016). Using Solution-Focused Dramatic Empathy Training to Eliminate Cyber-Bullying. Journal of Creativity in Mental Health, 11 (3-4), 378-390.

[17] Wong-Lo, M., Bullock, L. M., Gable, R. A. (2011). Cyber bullying: practices to face digital aggression. Emotional and Behavioural Difficulties, 16 (3), 317-325. doi: 10.1080/13632752.2011.595098

[18] Wellner, M. (2015). What can parents do about cyber bullying? Guest column. Capital, D.3.

[19] Schultze-Krumbholz, A., Gobel, K., Scheithauer, H., Brighi, A., Guarini, A., Tsorbatzoudis, H. et. al. (2014). A Comparison of Classification Approaches for Cyberbullying and Traditional Bullying Using Data From Six European Countries. Journal of School Violence, 14 (1), 47-65. doi: 10.1080/ 15388220.2014.961067

[20] Altobelli, T. (2010). Cyber-abuse - a new worldwide threat to children's rights. Family Court Review, 48 (3), 459-481. 